Nunt. Antiquus, Belo Horizonte, v. 14, n. 2, p. 91-109, 2018

\title{
Traduzir 0 intraduzível: 0 caso das partículas gregas
}

\author{
On Translating the Untranslatable: \\ The Greek Particles in Evidence
}

\section{Simone Bondarczuk}

Universidade Federal do Rio de Janeiro (UFRJ), Rio de Janeiro, Rio de Janeiro / Brasil simonebondarczuk@gmail.com

\begin{abstract}
Resumo: Na contramão do "dogma da intraduzibilidade” linguística de Jakobson (1959), este artigo se propõe a discutir a questão da possibilidade de ser do estrangeiro, no acolhimento proporcionado pela hospitalidade linguística sob o viés da tradução, sob a ótica da ressignificação do mito de Babel proposta por Ricœur (2012). Nessa perspectiva, o tradutor - como mediador ativo desse processo de aproximação do estrangeiro (autor, obra, sua língua) ao leitor - redescobre o seu lugar próprio em um projeto universal de humanização. A tradução como processo de humanização visa produzir semelhanças cujo escopo é identificar o si mesmo como um outro. As partículas gregas constituem um exemplo emblemático de uma classe de palavras típica da coloquialidade do Grego Antigo - atualmente conhecidas como marcadores discursivos -, que, no entanto, foi desprezada por uma tradição gramatical pautada nas categorias aristotélicas e na suposta correspondência um-a-um dos semantemas, impossível de ser mantida nesse caso. Sendo assim, as partículas gregas são apresentadas de modo a exemplificar a classe dos chamados tradicionalmente "intraduzíveis": não no sentido daquilo que não se pode traduzir, ao qual se nega a possibilidade de tradução, mas como uma classe de palavras que, a despeito do desprezo da tradição clássica, insistimos em traduzir de muitas maneiras distintas, já que se trata de palavras cujos sentidos são discursivamente determinados e de baixo valor conteudístico.
\end{abstract}

Palavras-chave: tradução; tradição; "intraduzível”; partículas gregas.

Abstract: Despite of Jakbson's (1959) "dogma of linguistic untranslatability", this article proposes to discuss the possibility of being for the foreigner in the light of the reception provided by translation's linguistic hospitality, from the point of view of the resignification of Babel's myth by Ricœur (2012). According to this perspective, the translator - as an active mediator of this process of bringing together the foreigner (author, work, language) and the reader - rediscovers his own place in a universal 
project of humanization. Translation, as a process of humanization, seeks to produce similarities whose scope is to identify oneself as another, that is, the identity under the diversity. The Greek particles constitute an emblematic example of a class of words typical of the colloquialism of the Ancient Greek Language - currently known as discursive markers - which, however, was neglected by a grammatical tradition based on the Aristotelian categories and the supposed one-to-one correspondence of the semantics, although impossible to maintain in this case. Thus, the Greek particles will be presented to exemplify the class of the traditionally so-called "untranslatable", not in the sense of what cannot be translated, but as a class of words that, despite the contempt of the Classical Tradition, we insist on translating in many different ways, since they are low content-value words whose meanings are determined by the discourse.

Keywords: translation; tradition; "untranslatable"; Greek particles.

\section{Introdução}

Neste artigo, nos propomos a resgatar um olhar, menos técnico e mais humano, sobre a tarefa da tradução de modo a revelar um pouco da beleza da diversidade linguística, especificamente do Grego Antigo, na esperança de que nos sirva de incentivo à resistência como profissionais das áreas de humanas - e, particularmente, da área de Letras Clássicas - ao preconceito linguístico. O tema do multilinguismo ${ }^{1}$ em nosso país, embora não faça parte do escopo deste ensaio, não deixa de ser contemplado na releitura do mito de Babel que aqui se apresenta. $\mathrm{Na}$ "porta do céu", miríades de línguas fragmentam a experiência humana e se constituem em abertura simbólica de uma universalidade perdida. Diante disso, só a possibilidade de existência do estrangeiro pode mover o ofício do tradutor, seja ele amador ou profissional.

Para ilustrar a resistência ao estrangeiro envolvida no processo tradutório - marcadamente acentuada pelo medo ocidental de se produzir uma cópia de má qualidade -, o caso das partículas gregas serve de exemplo singular de resistência ao estrangeiro por parte do tradutor, uma vez que o seu uso implica em recortes sintáticos e semânticos diferentes entre as línguas. Igualmente se constitui em um estudo de caso singular

\footnotetext{
${ }^{1}$ Refiro-me, aqui, não apenas às diversidades regionais do português, como as línguas dos imigrantes radicados no país, mas, principalmente, à diversidade das línguas ameríndias, muitas em processo de extinção.
} 
para confirmar a teoria da não equivalência absoluta entre as línguas, em relação às quais apenas podemos supor uma equivalência presumida, "não fundada numa identidade de sentido demonstrável, uma equivalência sem identidade", nas palavras de Ricœur (2012, p. 64).

Em primeiro lugar, fixemos o nosso olhar na bela imagem do conto de Borges, "A biblioteca de Babel” (2007), no qual o poeta descreve o mundo inteiro, o lugar da morada do homem, como uma grande biblioteca de células hexagonais contíguas que se estendem em todas as direções e existe $a b$ aeterno. Nesse universo, a viagem da existência humana perpassa pela busca infinita de livros e mais livros imaginados e desejados; nas palavras de Borges (2007, p. 40), ela se constitui de: "tudo o que é dado expressar: em todos os idiomas", "a versão de cada livro em sua própria língua”. Os idiomas de todos os tempos e lugares, reais ou imaginados, estariam ali representados. Nessa biblioteca, que é o universo inteiro, por que todas as versões são pressupostas? A resposta talvez se encontre na própria narrativa de Babel. Ricœur é o defensor dessa tese, a qual, definitivamente, acolhemos. O pensador propõe a relação envolvida na tradução como uma espécie de parceria, em forma de uma tríade: o estrangeiro, o leitor e o tradutor:

Dois parceiros são de fato colocados em relação pelo ato de traduzir, o estrangeiro - termo cobrindo a obra, o autor, sua língua - e o leitor, destinatário da obra traduzida. E, entre os dois, o tradutor [...]. É nessa desconfortável situação de mediador que reside a prova em questão. (RICEUR, 2012, p. 22).

Várias questões surgem dessa parceria: quais as implicações da noção de estrangeiro? O leitor como parte do processo tradutório? A situação desconfortável do tradutor como mediador?

Em diálogo com o texto de Ricœur, pensemos, por ora, na própria condição de possibilidade da existência do estrangeiro como condição sine qua non da tradução, a partir do mito de Babel. A questão central se torna: quem é esse estrangeiro que se quer traduzir? 


\section{0 mito de Babel revisitado}

Acolher o estrangeiro em nossa própria língua (para usar as palavras de Ricœur) nos parece prática essencial à sobrevivência de nossa humanidade, uma humanidade por vezes ameaçada pelo "pecado" da hegemonia linguística e política, arrogância transmutada, muitas vezes, em etnocentrismos linguísticos. Para admitirmos a existência do estrangeiro temos de buscar, pela via oposta, uma possibilidade de releitura positiva do mito etiológico de Babel. Na narrativa bíblica, in illo tempore, "todo mundo usava uma só língua e as mesmas palavras" (Gênesis, 11:1-9), mas Javé não estava satisfeito com o monolinguismo porque os homens pretendiam se tornar célebres pelos seus feitos e jamais serem dispersos, desejavam com ardor construir grandes torres que reafirmassem a sua supremacia linguística e territorial, tornando-se, assim, uma voz monocórdia.

Por conseguinte, em Babel - que significa "a porta do céu" -, a confusão-dispersão tornou-se a possibilidade divina do reconhecimento da alteridade radical de nossa humanidade, enriquecida na e pela diversidade linguística: "e o Senhor os dispersou dali por toda a superfície da terra" (Gênesis, 11:1-9b) e surge assim a figura do estrangeiro. Não existe mais o idêntico, agora somos também o outro em sua estrangeirice; a propósito: "fomos colocados em movimento pelo fato da pluralidade humana" (RICEUR, 2012, p. 55). Fato esse que se transmutou em toda nossa redenção. O desafio desde então é traduzir, não somente um sistema de signos, mas a radicalidade da diferença que, de modo contrastivo, nos permite definir a nossa própria identidade linguística.

A tarefa da tradução assume um duplo empenho: a restauração de uma unidade linguística originária que só pode ser contemplada no pressuposto de uma complementariedade essencial entre as línguas; e o acolhimento do estrangeiro em sua própria língua, em uma espécie de solidariedade cósmica que compreende a importância da diversidade na unidade e da unidade na diversidade. Sendo assim, tanto a pulsão de traduzir adquire uma justa explicação, quanto a incomunicabilidade entre as línguas é vista de modo complementar e não excludente. Para além disso, restaurada a positividade do mito de Babel, floresce a beleza 
da diversidade linguística, e o tradutor reencontra seu lugar próprio no mundo: aquele que deve fazer as honras da hospitalidade linguística.

Fazer as honras também possui um duplo sentido: de sentirse honrado por poder receber o estrangeiro em sua própria língua; e reconhecer nesse encontro fraterno a alteridade radical, não como ameaça, mas como possibilidade de enriquecimento da própria língua. Em outras palavras, reconhecer que o que outro disse em sua língua na nossa pode ser dito tão bem quanto, se percebo a nossa identidade naquelas diferenças, ao buscar uma equivalência da beleza presumida no outro, ou seja, se não pudermos nos encantar com a diferença, não podemos reconhecer e reproduzir a sua beleza.

Ancorados nessa perspectiva teórica, propomos algumas vias possíveis, em consonância com Ricœur, para a mediação do tradutor se tornar menos desconfortável:

1) renunciar ao ideal da tradução perfeita - as traduções são sempre aproximativas e são bem-sucedidas na medida em que alcançam a sua finalidade proposta;

2) acolher o estrangeiro na sua estrangeirice (hospitalidade linguística);

3) substituir a alternativa teórica: traduzivel versus intraduzivel pela fidelidade versus traição, considerando que ser fiel ao estrangeiro não deve implicar em traição à própria língua, mas em potencialização de suas possibilidades, buscando uma equivalência presumida;

4) não admitir critério absoluto de boa tradução (o que não significa que não haja bons critérios que poderiam ser admitidos);

5) admitir que uma boa tradução só pode visar uma equivalência presumida - uma equivalência que considera a alteridade, porque é necessário reconhecer a alteridade radical do outro e acolhê-la na nossa diferença.

Todos esses princípios dizem respeito muito mais à atitude do tradutor do que a um aporte técnico específico de tradução, devem permanecer como um ponto de referência e serão melhor ilustrados em nossa análise do caso das partículas. 
Além disso, outra questão pertinente trazida por Ricœur (2012, p. 46) aponta: "para que se pudesse dispor de tal critério [absoluto] seria preciso poder comparar o texto de partida e o texto de chegada a um terceiro texto portador de sentido idêntico àquele que se supõe circular do primeiro ao segundo". Bem, não há um terceiro texto, embora alguns suponham que uma tradução interlinear cumpra esse papel falacioso. Uma alternativa viável para cobrir esse hiato talvez fosse o tradutor produzir notas com comentários que julgasse necessários à compreensão do leitor, a partir das quais o terceiro texto seria uma construção do leitor.

\section{Velhos problemas: De finibus bonorum et malorum}

Bem, tracemos uma linha pontilhada na história da tradução no Ocidente, marcando alguns pontos relevantes. Na Antiguidade tardia, os primeiros tradutores foram os latinos, que, ao submeterem politicamente os gregos, também foram conquistados pela sua riqueza cultural e literária e procuraram recompô-la em sua própria língua. O caso latino ilustra, em certa medida, a contraparte da beleza da hospitalidade linguística que é a resistência à tradução como resistência à aceitação do estrangeiro.

Ricœur, em seu livro Sobre a tradução, nos chama atenção para esse perigo grave e ainda mais ameaçador em tempos de intolerância, assinalando que:

A pretensão à autossuficiência e a recusa da mediação do estrangeiro nutriram em segredo muitos etnocentrismos linguísticos e, o que é mais grave, muitas pretensões à hegemonia cultural, tal como se pôde observar da parte do latim, da Antiguidade tardia ao fim da Idade Média e mesmo além do Renascimento [...]. (RICEUR, 2012, p. 23).

Para que se possa dimensionar esse etnocentrismo, tomemos como exemplo um grande escritor latino, Cícero, um dos poucos que nos legou reflexões sobre a tarefa de traduzir, como também o fizeram Horácio e Quintiliano.

Ora, Cícero não escreveu nada que dissesse respeito diretamente à tradução, no entanto podemos destacar, de algumas de suas obras, 
importantes comentários sobre o seu labor tradutório, dando indicativos de alguns de seus pressupostos na tradução, os quais se revestem de um interesse especial para a filosofia, se considerarmos que Cícero foi o criador de um vocabulário filosófico latino e, com isso, consolidou uma tradição no Ocidente, quando se propôs a verter a filosofia grega para a sua própria língua.

Quanto à tradução de obras filosóficas, outro problema se apresenta: como traduzir termos que, ao serem empregados, se apresentam como verdadeiros "fenômenos de intertextualidade" (RICEER, 2012, p. 25), como é o caso dos diálogos platônicos? Ricœur (2012, p. 25) define essa intertextualidade como "retomada, transformação, refutação de empregos anteriores por autores vindos da mesma tradição de pensamento ou de tradições adversas". Um mesmo termo que condense todas essas tensões obviamente não pode ser traduzido por um único termo-chave, portanto a questão permanece em aberto ad infinitum e a biblioteca de Babel continua se expandindo nessa perspectiva.

Cícero se inscreve nessa tradição de possibilidades, portanto o comentário escolhido para este artigo se encontra presente em De finibus bonorum et malorum ( $A$ respeito dos fins do bem e do mal, título de inspiração socrática: qual o fim supremo da vida do homem?; mas em uma leitura aristotélica, pensando como uma hierarquia de bens e males).

Resumidamente, a obra em questão diz respeito aos princípios éticos dos três principais sistemas filosóficos da época: o Epicurismo, o Estoicismo e o da Academia Nova sob a direção de Antíoco. O plano de Cícero era tornar claro o pensamento de cada escola filosófica e o discurso de seus opositores. A obra foi construída em forma de três discursos separados: a primeira parte sobre o Epicurismo, a segunda sobre o Estoicismo e a última sobre o tempo que esteve em Atenas na Academia sob a direção de Antíoco.

Mas o que nos interessa é o modo como Cícero concebe a tradução e o modo de transmitir culturalmente essas correntes de pensamento; observemos o excerto:

No entanto, se eu vertesse de modo absoluto [plane sic verterem] Platão ou Aristóteles, tal como nossos poetas verteram as peças de teatro, estaria, creio 
eu, servindo mal aos meus concidadãos [mererer], ainda que eu trouxesse ao seu conhecimento aqueles intelectos divinos. Mas isso não fiz até agora, e, contudo, não me considero proibido de fazê-lo. Algumas passagens, certamente, caso me pareça bem, transportarei para minha obra, principalmente aquelas que nomeei ainda há pouco; e, quando houver ocasião em que possa se fazer de modo apropriado, como costuma Ênio traduzir Homero, e Afrânio, Menandro. (CÍCERO, De finibus bonorum et malorum, I, 7. Tradução e grifos meus).

Cícero usa o verbo vertere para indicar o que se entende hoje como tradução, mas a palavra em seu sentido primeiro significava "virar" - quando os romanos se referiam a virar ou revirar a terra com o arado para prepará-la para o plantio. A extensão metafórica desse sentido aponta para uma transformação de um estado em outro.

O fato de Cícero aplicar tal verbo a uma obra filosófica implica na produção de um novo texto sem compromisso com a manutenção da forma originária, o que fica claro no uso feito por ele do advérbio de modo plane ("inteiramente, absolutamente"), negando, por meio deste, a possibilidade de que seja feita uma transposição em absoluto de Platão ou Aristóteles. Sendo assim, conclui-se que a expressão plane sic verterem refere-se à nossa concepção moderna de tradução, a qual ele rejeita, pois para Cícero fidelidade ao original, nesse caso, implicaria em traição aos seus concidadãos, aos quais estaria servindo mal se o fizesse. Nesse caso, poder-se-ia dizer que o que está em questão é o dilema da tradução: fidelidade versus traição, mas infelizmente esse dilema aqui é secundário.

Para além desse paradoxo, estende-se o problema do etnocentrismo cultural. Esse mesmo autor em outras obras ${ }^{2}$ reafirma a supremacia da

${ }^{2}$ CÍCERO, Discussões Tusculanas (I, I, 1). Também em De finibus (I. 5-6), Cícero argumenta que não vai agir como um interpretum ("tradutor"), mas, de fato, transportar o pensamento e as discussões dos antigos para o latim. Nesse excerto, o método de Cícero é simplesmente basear-se nos modelos gregos e recriar na língua latina, com o contexto, a língua, os temas e modos romanos. Ele se expressa dessa forma: nostrum iudicium et nostrum scribendi ordinem adiungimus. 
língua e da cultura latina sobre a grega. Por conseguinte, a expressão "velhos problemas" refere-se a toda forma de ideologia política dominante ou imperialista refletida nas formas de traduzir.

\section{Primeiros parâmetros para a tradução: Leonardo Bruni Aretino}

No início do Renascimento, ${ }^{3}$ surge no cenário erudito Leonardo Bruni Aretino (1374-1444), escritor, político, filólogo, filósofo, historiador, professor de retórica e tradutor. Interessa-nos neste artigo sua experiência e teorização sobre a tradução, pois de forma contundente foi esse erudito o precursor das teorias e manuais modernos de tradução. A partir de uma ótica preciosista, abordou a tradução como um ofício artístico e retórico, além de muito preciso e que não poderia prescindir de uma técnica acurada, com ênfase na preservação da retórica e beleza estética do texto original. Seu preciosismo advinha, em parte, do fato de ser perfeito conhecedor do grego, portanto começa o ensaio elogiando a sua tradução latina da Ética Nicomaqueia e criticando pesadamente outra tradução anterior, feita por Roberto Grosseteste. Destaca-se o seu profundo conhecimento de grego como ferramenta definitiva para formar as bases do Humanismo, ao direcionar o movimento humanista para uma retomada dos autores gregos e de suas obras originais.

Ora, o texto De interpretatione recta (1420 a 1426) foi considerado o primeiro tratado moderno a refletir sobre a tarefa de traduzir, em especial sobre a tradução literária. Bruni pressupõe a existência da forma correta de traduzir, a qual seria capaz de captar a intenção do autor revelada tanto na forma quanto no conteúdo. Propõe assim que o tradutor deva traduzir de forma correta (definido no uso de recta) e não aproximada; há um ideal de perfeição que perpassa todo este ensaio. Falar da intenção do autor original é tarefa difícil se não refletirmos sobre os parâmetros formais (linguísticos, discursivos, retóricos, literários) para proceder a essa análise crítica.

\footnotetext{
${ }^{3}$ Há um consenso entre os estudiosos de que não houve na Idade Média uma reflexão sistemática sobre os princípios de tradução, apenas comentários esparsos cujo modelo tradicional ainda tinha como base a tradução de São Jerônimo.
} 
Nesse texto, pela primeira vez se documenta a palavra traduco, que podemos equiparar ao plene sic vertere de Cícero. A expressão usada por Bruni é recte traducatur, "seja traduzido corretamente", ou interpretatio recta, "correta tradução". Bruni, em alguma medida, será o responsável no Ocidente por estabelecer o ideal de tradução absoluta, no momento em que nos lega os parâmetros aceitos até a modernidade como ideais.

O pensamento de Bruni - no comentário de Furlan sobre a sua tradução de De interpretatione recta - é a culminação de uma tradição em desenvolvimento, ao menos um século antes, sobre a concepção do modo de traduzir. Segundo Bruni, o tradutor deve insistir nos três requisitos para uma boa tradução, expostos anteriormente pelo franciscano inglês Roger Bacon (ca. 1214-1294) em sua obra Opus Maius (em particular na terceira parte, intitulada De utilitate grammaticae), a saber: o conhecimento tanto da língua de partida como da língua de chegada, bem como da matéria envolvida na tradução. Logo, Bacon recusa radicalmente a tradução ad uerbum (palavra por palavra). Na perspectiva de Ricœur, seria o equivalente a pensar a relação entre o estrangeiro (o autor, sua língua e cultura) e o receptor/leitor, sendo sensível a radicalidade das diferenças linguísticas; contudo Bruni vai sustentar um ideal absoluto e artisticamente refinado para a tradução.

Além dos elementos linguísticos, o tratado bruneano insiste sobre os aspectos retóricos de uma tradução - a base da fundação da moderna tradução literária. A exigência da reprodução dos aspectos artísticos para uma correta tradução impõe o conhecimento tanto dos recursos retóricos (privilegiando a retórica latina) quanto dos oratórios, além do conhecimento linguístico e filológico de ambas as línguas.

Seguem-se resumidamente os seus princípios:

1) O conhecimento da língua de partida: o tradutor deve ser um perito, um especialista em diversos gêneros e escritores, apreendidos pela prática da leitura;

2) O conhecimento da língua de chegada: propõe um domínio absoluto da língua de chegada e rejeita veementemente que se deixe a palavra no original por ignorância de um equivalente justo, 
e preconiza: "que conheça acuradamente a força e a natureza das palavras", um ideal quase platônico.

3) O conhecimento da matéria envolvida na tradução: esse parece evidente demais para não ser aceito como critério e segue a tradição horaciana: "domina o assunto e as palavras o seguirão" (Ars Poetica, vv. 40-41).

4) O uso do ouvido ou "ritmo" e "harmonia": a reprodução do estilo depende de uma sensibilidade estética. Esse requisito diz respeito à compreensão e reprodução artística do original, dependente de uma escuta atenta à harmonia e ao ritmo (mesmo para prosa precisamos ter "ouvido").

Em síntese, pela primeira vez o ofício do tradutor é reconhecido como uma técnica que deve ser desenvolvida com diligência e arte, se se pretende atingir a intenção do autor em suas finalidades retóricas de convencimento. A impressão que permanece da leitura de $D e$ interpretatione recta é que não bastaria uma vida para estarmos prontos a cumprir tal perfeição na arte da tradução.

\section{Traduzindo o intraduzível: 0 caso das partículas gregas}

Bem, chega o momento de aplicarmos essa curta reflexão teórica ao nosso objeto de estudo: as partículas gregas. As partículas se enquadram no que chamamos de intraduzíveis por duas vias: pela tradição gramatical clássica, que as ignorou, considerando-as como elementos não traduzíveis e, portanto, dispensáveis; e como uma classe de palavras que, a despeito do desprezo da tradição clássica, insistimos em traduzir de muitas maneiras distintas. Mas o que precisamente são as partículas? E como devem ser abordadas numa tradução?

Dionísio Trácio (gramático do I séc. a.C.) foi quem designou algumas partículas como conjunções "expletivas", ${ }_{4}^{4} \sigma u ́ v \delta \varepsilon \sigma \mu o \imath$

\footnotetext{
${ }^{4}$ As expletivas são as empregadas com finalidade métrica ou meramente ornamental.

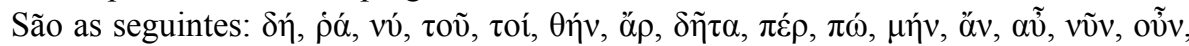
$\kappa \varepsilon ́ v, \gamma \varepsilon \dot{\varepsilon}$. Alguns incluem entre estas as conjunções adversativas, tais como $\check{\varepsilon} \mu \pi \eta \varsigma$ e ö $\mu \omega \varsigma$

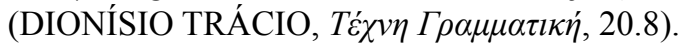


$\pi \alpha \rho \alpha \pi \lambda \eta \rho \omega \mu \alpha \tau \iota \kappa o i ́$, que são as empregadas com finalidade métrica ou meramente ornamental, pois elas não adicionavam conteúdo proposicional à sentença. Na opinião de Hoogeveen (1769), partindo dessa classificação de Dionísio, partículas até então consideradas supérfluas, na realidade, tinham um propósito diverso, incluído no âmbito do que é considerado vultus ("expressão facial"), gestus ("gesto") ou vocis ductus ("entonação"), que acompanham um sentença. Entre os conceitos invocados na sua explicação aparecem: emphasis ("ênfase"), confirmatio ("confirmação"), affirmatio ("afirmação"), limitatio ("restrição") e perspicuitas ("evidência"), todo um aparato semântico que permaneceu basicamente inalterável até o século XX, quando da escritura da obra sistemática de J. D. Denniston sobre esses elementos gramaticais. Singular esse testemunho de como já em período helenístico (no qual o estrangeiro precisa aprender o grego), as partículas teriam sido consideradas elementos meramente decorativos. Quem decide o que pode ser considerado supérfluo em uma língua estrangeira?

Desde então, a mais detalhada e extensa descrição dos usos das partículas encontra-se, sem dúvida, na obra de J. D. Denniston, The Greek Particles (2. ed. 1954). O livro surpreende pela descrição no uso das partículas, abrangendo praticamente todos os textos conhecidos da literatura grega antiga e preenchendo uma lacuna neste estudo; embora o próprio autor reafirme mais o seu caráter estilístico-literário do que gramatical. Os dois volumes tornaram-se um ponto de referência para todas as pesquisas posteriores, utilizados pelos especialistas mais ou menos como uma enciclopédia ou manual de consulta rápida, apesar de nem todas as partículas e suas possíveis combinações terem sido contempladas nesta obra e, também, de haver uma sobreposição de valores semânticos, sem preocupação em fazer distinções de uso entre partículas de valores aparentemente semelhantes.

Segundo Denniston, no período clássico da literatura grega (V-IV séc. a.C.), com o desenvolvimento da prosa ática, as partículas assumem um papel muito mais significativo no modo de expressão da estrutura frasal, sendo usadas isoladamente, ou numa série de combinações, e gerando uma polissemia em seus diversos usos, geralmente vinculados à subjetividade discursiva do falante/escritor e a contextos pragmático- 
discursivos bem específicos, de modo que esse será o período contemplado por este artigo. Deixamos de lado os textos poéticos por estarem estritamente condicionados à métrica e a um ritmo particular que certamente influencia na escolha das partículas; no afã de procurar uma equivalência presumida, mesmo sem identidade, esses fatores devem ser considerados.

A dificuldade de encontrarmos uma definição exata de partículas reside no fato de elas não se constituírem em uma classe de palavras no sentido restritamente aristotélico, uma vez que seu significado e função precisos surgem nos contextos de uso. Além disso, elas englobam palavras pertencentes a diversas classes gramaticais da gramática tradicional: advérbios, conjunções, pronomes, interjeições, etc. Entretanto, podemos defini-las, como faziam os primeiros gramáticos, inicialmente como

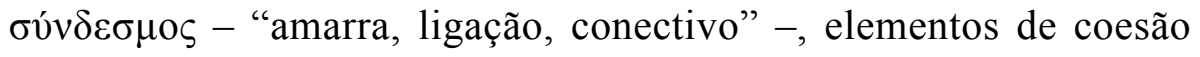
discursiva cuja função deve ser entendida de forma ampla, como conectores de sintagmas, de partes do discurso e de discursos inteiros.

Outra dificuldade relacionada a descrições das partículas é a sua extrema versatilidade e fluidez na tradução, porque elas geralmente aparecem tendo uma série de diferentes funções e significados, dependentes do contexto discursivo, entre os quais as relações não são sempre imediatamente claras. Gerações de especialistas têm tratado as partículas como itens altamente polissêmicos, restringindo suas discussões a meras listas de significados aparentemente não relacionados aos usos nos contextos discursivos ou não claramente relacionados a eles (e, no caso do latim e do grego, também recorre-se a explicações da etimologia, conquanto algumas sejam incertas e outras difíceis de relacionar aos seus usos). Esse modo de proceder se chama abordagem maximalista de partículas.

A partir dos resultados do trabalho feito pelo grupo de pesquisa de Amsterdã, ${ }^{5}$ de orientação principalmente pragmática, os estudos

\footnotetext{
${ }^{5}$ Ruijh fundou a escola filológica de estudos sobre as partículas em Amsterdã, cujos frutos dos trabalhos, nesses últimos quarenta anos, têm sido expressivos e uma fonte relevante para estudiosos das partículas. Seus pesquisadores se concentraram no estudo funcional de algumas partículas específicas, do ponto de vista sincrônico, em uma abordagem minimalista, não tendo a pretensão de Denniston de cobrir uma vasta gama de partículas em todos os autores gregos da Antiguidade. Outro importante campo de estudo
} 
de partículas tendem a proceder de uma posição minimalista que é caracterizada por uma minimização da semântica e uma maximização da pragmática.

Como as partículas são dependentes do contexto discursivo, impõe-se uma definição de ato discursivo, porque um grande empecilho para a compreensão mais adequada da natureza das partículas é tentar percebê-las como ornamentos literários somente e não como elementos construtores de um discurso. Nessa nova abordagem teórica, a noção de discurso é central. Hannay e Kroon (2005, p. 121) definem como ato discursivo os passos distintos executados pelo produtor do discurso como resultado de um planejamento estratégico, de modo a realizar uma determinada intenção comunicativa. De um ponto de vista pragmático, em um diálogo, cada turno de fala é uma enunciação que pressupõe: (1) certas intenções comunicativas, abordadas como télos literário e também filosófico; (2) e também uma performatização de certas estratégias, no caso dos diálogos platônicos - um modo de construir a argumentação, caracterizado tanto pelo élenkhos socrático, quanto pelo exercício dialético. Sendo assim, as partículas não devem ser ignoradas nas traduções, embora algumas exceções possam ser admitidas. Levando em consideração suas funções claramente discursivas, as partículas são consideradas atualmente como verdadeiros marcadores discursivos.

É viável, portanto, a aplicação do conceito de marcadores discursivos no contexto linguístico da Antiguidade Clássica, tendo em vista que esses mesmos marcadores se inserem em um âmbito de oralidade latente, ou seja, em um mundo cultural (V-IV séc. a.C.) onde os textos escritos ainda seriam elaborados com vista à leitura em voz alta. A leitura, por sua vez, necessitava da intervenção da voz leitora os textos eram em escrita contínua e sem pontuação - para conferir a entoação, imprescindível para o entendimento pretendido pelo autor. Nesse sentido, pode-se supor que as partículas deveriam ser de grande

abordado por essa escola é o da filologia e da crítica textual, porque frequentemente são os editores dos manuscritos gregos que têm de decidir a acentuação das partículas em determinado manuscrito. Entre esses estudiosos encontram-se nomes importantes como: Sicking e Van Ophuijsen, Egbert J. Bakker, Albert Rijksbaron e outros. 
valia para o processo de leitura, funcionando, muitas vezes, como uma verdadeira pontuação oral.

De fato, as partículas possuem pouco conteúdo semântico; no entanto Schiffrin (1992) mostrou que os marcadores discursivos não são vazios de significação, embora, às vezes, seus significados, por serem contextualmente dependentes, não sejam facilmente recuperáveis. Mesmo assim eles são essenciais para o aperfeiçoamento retórico de qualquer argumento ou narrativa e recursos fundamentais para assinalar a coerência discursiva. Lenk ressalta que:

[...] as conexões [entre os turnos] não são sempre claramente reconhecíveis, a menos que elas sejam propriamente indicadas. A falta dessa indicação impede que os analistas - e algumas vezes os participantes de uma conversação - compreendam as suas diferentes partes como sendo coerentes. (LENK, 1998, p.3).

Essa afirmação mostra como os conectivos ou marcadores discursivos são elementos imprescindíveis em uma conversação para orientar a interpretação do interlocutor/leitor; o mesmo ocorre em escritos que buscam reproduzir ou simular uma conversação, assim como acontece na maioria dos diálogos platônicos. Para exemplificar tal importância do uso das partículas, apresentamos o seguinte excerto do diálogo Filebo:

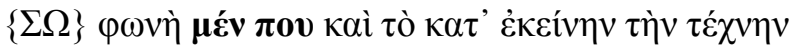

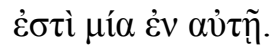

$\{\Pi P \Omega\} \pi \tilde{\omega} \varsigma \delta$ ' ovँ;

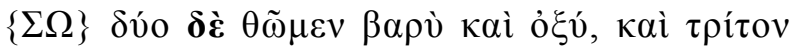

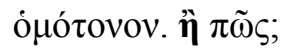

$\{\Pi P \Omega\}$ oṽ $\tau \omega \varsigma$.

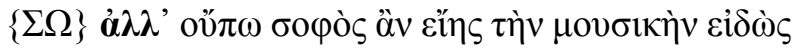

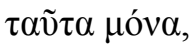

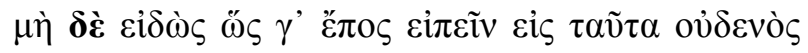

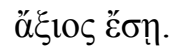


Sócrates: A voz, de algum modo, e, de acordo com essa técnica, também é uma em si mesma...

Protarco: E como não?

Sócrates: Ainda assim, estabeleçamos, dois [tons], um grave e um agudo, bem como um terceiro tom, uníssono. Ou como seria?

Protarco: Assim mesmo.

Sócrates: Bem, mas desse modo não serias um sábio em relação à música por saber somente essas coisas; porém, não serias confiável, por assim dizer, se não soubesses nada sobre isso. (PLATÃO, Filebo, $17 \mathrm{c}$. Tradução e grifos meus).

Nesse exemplo, temos uma combinação de partículas estruturada

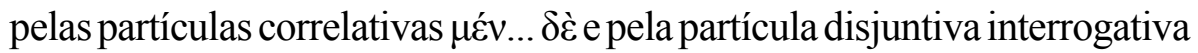
ทे. Ao serem associadas formam, nesse contexto, uma construção do tipo: por um lado $(\mu \varepsilon \dot{v} v) X$, enquanto $(\delta \grave{\varepsilon})$ Y ou possivelmente (ì) Z. Esse tipo de construção parece recorrente em Platão e típica do diálogo filosófico, pois aqui a partícula disjuntiva não introduz um segundo elemento, como em seu uso gramatical mais comum, mas a possibilidade de uma terceira alternativa aos dois argumentos precedentes ou ainda um terceiro possível elemento na argumentação que está sendo posta sob interrogação. Ao mesmo tempo em que assinala uma abertura, não deixa de lançar uma dúvida sobre a validade dessa terceira alternativa, ao ser usada junto a um advérbio interrogativo $(\pi \tilde{\omega} \varsigma)$. Isso é confirmado pela partícula $\alpha \lambda \lambda \alpha$, que se segue imediatamente aos dois primeiros pares adjacentes, e chama a atenção para o fato de Protarco responder de forma assertiva que os dois argumentos eram mesmo os propostos, não aceitando a sugestão de uma terceira possibilidade, assinalada pela partícula disjuntiva; enquanto o uso de $\alpha \lambda \lambda \alpha$ ń nesse caso marca uma correção: embora eles estejam de acordo, isso ainda não é suficiente para se estabelecer adequadamente o argumento. Quanto à partícula $\delta \dot{\varepsilon}$, ela amplia a sentença proposta por $\mu \varepsilon \dot{v}$, acrescentando um novo desdobramento. ${ }^{6}$

\footnotetext{
${ }^{6}$ Segundo as observações de Ruijgh (Autour de "te èpique": études sur la syntaxe grecque), em seus estudos sobre a prosa de Heródoto, o valor fundamental de dé, usado
} 
Também é interessante notar, nesse excerto, que Platão utiliza uma estratégia linguístico-discursiva para simular as interrupções do discurso com respostas ou perguntas curtas e acentuar o caráter conversacional do embate filosófico, pretendendo recriar, na escrita, uma mimese da conversação onde as interrupções são comuns. $\mathrm{O}$ assentimento de Protarco se encontra entre as partículas correlativas $\mu \dot{\varepsilon} v \ldots \delta \dot{\varepsilon}$, em duas falas consecutivas de Sócrates, revelando o caráter paratático próprio dessa construção. O uso das correlativas, nesse caso, denota uma unidade de pensamento interrompida ou posta em suspensão.

Outro exemplo relevante para mostrar a importância de não se ignorar as partículas sem prejuízo da compreensão do texto encontra-se no Sofista 265a-b. Nesse contexto, o Estrangeiro, ao falar da arte mimética, estabelece o sentido de mimese para depois expô-lo ao exame, dizendo assim:

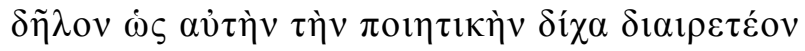

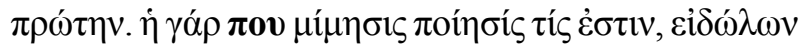

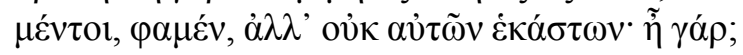

É evidente que se deve primeiro dividir em duas a arte poética; pois, em certa medida, a mimese é uma criação, certamente de imagens, como costumamos dizer, mas não de cada uma das próprias coisas; não é assim? (PLATÃO, Sofista 265a-b. Tradução e grifos meus).

No excerto acima, a partícula $\pi$ ov (que expressa certa dúvida) cumpre um papel fundamental para relativizar a afirmação de que a mímēsis é uma poiésis (uma criação), afirmação essa que, sem a presença da partícula, causaria um estranhamento em um contexto de argumentação platônico.

isoladamente, consiste simplesmente em indicar que o segundo fato se acrescenta como um elemento novo a um fato já expresso, quer dizer, que marca uma transição no discurso (como o poi do italiano). Em síntese, a partícula assinala a adição de um segundo fato ao fato precedente, podendo ser uma explicação, uma ampliação, uma nova parte do discurso ou a repetição do discurso depois de uma digressão. Esses usos são observáveis também na construção $\mu \varepsilon \dot{v}$... $\delta \dot{\varepsilon}$, como pudemos constatar em nossa pesquisa. 
Por fim, esperamos ter ilustrado, ainda que de forma tênue, a importância de, no processo de considerarmos o estrangeiro, não ignorarmos categorias linguístico-discursivas de sua língua que levam em conta a pragmática e a prosódia dessa mesma. Tentar minimizar as distâncias culturais é levar a sério o estrangeiro em sua estrangeirice e procurar recriar de forma aproximativa em nossa língua um equivalente cultural, ao mesmo tempo, idêntico e estranho a nós mesmos, a alteridade na identidade.

\section{Referências}

BÍBLIA SAGRADA. Petrópolis: Vozes, 2005.

BONIFAZI, A. Homer's Versicolored Fabric: The Evocative Power of Ancient Greek Epic Word-Making. Washington, D. C.: Harvard University Press, 2012.

BORGES, J. L. A biblioteca de Babel. In: das Letras, 2007. p. 38-42. (Coleção Biblioteca Borges).

BRUNI ARENTINO, L. De interpretatione recta. Tradução de Mauri Furlan. Scientia Traductionis, Florianópolis, n. 10, p. 16-47, 2011.

BRUNI ARETINO, L. De interpretatione recta. In: BARON, H. (Hg.). Humanistisch-philosophische Schriften. Leipzig: Teubner, 1928. p. 1-32.

CÍCERO. Discussões Tusculanas. Tradução de Bruno Fregni Bassetto. Uberlândia: EDUFU, 2014.

DENNISTON, J. D. The Greek Particles. 2. ed. Oxford: Oxford University Press, 1954. 2 v.

HOOGEVEEN, H. Doctrina particularum linguae Graecae. Leiden: E. Typographeo Dammeano, 1769.

KROON, C. Discourse Particles in Latin. A Study of nam, enim, autem, vero and at. Amsterdam: Brill, 1995. (Amsterdam Studies in Classical Philology, 4).

PLATÃO. Filebo. Texto estabelecido e anotado por John Burnet. Tradução, apresentação e notas de Fernando Muniz. Rio de Janeiro: PUCRio; São Paulo: Loyola, 2012. 
PLATÃO. Sofista. Tradução de Henrique Murachco, Juvino Maia Juniro e José Trindade Santos. Prefácio, introdução e apêndice de José Trindade Santos. Lisboa: Fundação Calouste Gulbenkian, 2011.

RICEUR, P. Sobre a tradução. Tradução de Patrícia Lavelle. Belo Horizonte: UFMG, 2012.

RIJKSBARON, A. New Approaches to Greek Particles. Amsterdan: J. C. Gieben Publisher, 1997. (Amsterdam Studies in Classical Philology, 7). RÓNAI, P. A tradução vivida. Rio de janeiro: Nova Fronteira, 2000.

RUIJGH, J. C. Autour de "te èpique": études sur la syntaxe grecque. Amsterdam: Hakkert, 1971.

SICKING C. M.; OPHUIJSEN, J. M. van. Two Studies in Attic Particle Usage: Lysias and Plato. Leiden; New York; Köln: Brill, 1993.

Recebido em: 20 de setembro de 2018. Aprovado em: 5 de dezembro de 2018. 